\title{
Orthopaedic Sports Medicine Fellowship Directors Are Predominantly White Men With a High Degree of Research Productivity
}

\author{
M. Lane Moore, BS, Muhammad Ali Elahi, BS, Matthew K. Doan, BS, \\ Jordan R. Pollock, BS, Justin L. Makovicka, MD, MBA, Jeffrey D. Hassebrock, MD, \\ Joseph C. Brinkman, MD, and Karan A. Patel, MD
}

\begin{abstract}
Purpose: To determine the objective characteristics of fellowship directors (FDs) in orthopaedic sports medicine by focusing on the demographics, academic background, institutional history, research experience, and professional affiliations of FDs in this field. Methods: Data was collected for each FD via institutional biographies or publicly available curriculum vitae $(\mathrm{CV})$. The data collected for each FD included age, gender, race/ethnicity, previous training institutions, residency and fellowship graduation years, additional advanced degrees, military affiliation, institutional loyalty, year hired by current institution, career timeline, Scopus H-index, number of publications, and total number of citations. Results: Of the 88 FDs, $87(98.9 \%)$ were male and $1(1.1 \%)$ was female. The mean age for all FDs was 54.7 years $( \pm 9.1$ standard deviation). The majority of FDs were White $(\mathrm{n}=80 ; 90.9 \%)$. The mean Scopus H-index, total number of publications, and total number of citations were $22.5 \pm 16.6,90.0 \pm 91.6$, and $2773.9 \pm 3962.9$, respectively. On average, it took $9.5 \pm 7.3$ years from fellowship graduation until FD appointment. Additionally, the mean number of years of employment or affiliation with the current institution was $17.2 \pm 9.4$, and the mean number of years in an FD role was $10.9 \pm$ 9.3. Conclusion: Orthopaedic sports medicine fellowship directors are largely distinguished by their high level of research productivity and accomplishment. Additionally, orthopaedic training pedigree seems to play a role in FD role attainment, with a handful of orthopaedic residency and sports medicine fellowship programs producing a large percentage of current FDs. Finally, FDs are overwhelmingly white males with little female or minority representation. Clinical Relevance: This study outlines some of the most important characteristics among orthopaedic sports medicine fellowship directors and identifies racial and gender disparities within this population of leaders that may have detrimental effects on the field as a whole.
\end{abstract}

$\boldsymbol{S}_{\mathrm{p}}^{\mathrm{i}}$ ince the establishment of accredited fellowship programs by the Accreditation Council for Graduate Medical Education (ACGME) in 1985, the concentration of orthopaedic surgery has transitioned largely from general practice to specialized care. Since that time, the number of orthopaedic surgeons pursuing fellowships has greatly increased relative to number of practicing general orthopaedic surgeons. ${ }^{1-3}$ Illustratively, $90 \%$ of orthopaedic surgeons applying for board certification in 2013 had completed a fellowship, in contrast with $76 \%$ in $2003 .{ }^{4}$ As fellowships have

From the Mayo Clinic Alix School of Medicine, Scottsdale, Arizona, U.S.A. (M.L.M., M.A.E., M.K.D., J.R.P.); and the Department of Orthopedic Surgery, Mayo Clinic, Phoenix, Arizona, U.S.A. (J.L.M., J.D.H., J.C.B., K.A.P.).

The authors report the following potential conflicts of interest or sources of funding: J.D.H. reports personal fees, Goode Surgical Inc. K.A.P. reports personal fees, Arthrex. Full ICMJE author disclosure forms are available for this article online, as supplementary material.

Received February 15, 2021; accepted July 12, 2021. become more prominent in the field of orthopaedics, the influence of fellowship directors (FDs) on current and future surgeons has reached new heights. Possessing unique professional, academic, clinical, and research backgrounds, these directors are leaders in the field.

Many previous studies have sought to understand orthopaedic applicants and trainees. Such studies have examined topics such as the favorable qualities and accomplishments among medical students desiring a career in orthopaedics, factors influencing a student's

Address correspondence to Karan A. Patel, MD, Department of Orthopedic Surgery, Mayo Clinic, 5777 E. Mayo Blvd, Phoenix, AZ 85054, U.S.A. E-mail:patel.karan@mayo.edu

(C) 2022 THE AUTHORS. Published by Elsevier Inc. on behalf of the Arthroscopy Association of North America. This is an open access article under the CC BY-NC-ND license (http://creativecommons.org/licenses/by-nc-nd/4.0/). 2666-061X/21200

https://doi.org/10.1016/j.asmr.2021.07.006 
decision to pursue orthopaedics, and selection criteria for orthopaedic surgery applicants. ${ }^{3,5-10}$ However, few studies have examined the characteristics of leaders within the field of orthopaedic surgery. One such study sought to outline the gender disparity that exists within orthopaedic leadership and the many impacts it has on the field. ${ }^{1-13}$ Other studies have characterized the leadership qualities of plastic surgeon FDs and orthopaedic FDs in spine surgery and adult reconstruction. ${ }^{14-16}$ However, no previous analyses have been done in the field of orthopaedic sports medicine.

Although orthopaedic sports medicine fellowship directors possess an extensive array of leadership skills, the objective benchmarks that distinguish these physicians are unclear. The purpose of this study was to determine these objective characteristics of fellowship directors in orthopaedic sports medicine by focusing on the demographics, academic background, institutional history, research experience, and professional affiliations of FDs in this field. Our hypothesis was that if the FD position in orthopaedic sports medicine fellowship programs is as competitive and prestigious as other related fields, then we will expect to see FDs with a high level of research productivity and accomplishment. Additionally, we hypothesize that the demographic makeup of orthopaedic sports medicine FDs will be relatively homogeneous, like the orthopaedic field as a whole.

\section{Methods}

The American Orthopaedic Society for Sports Medicine (AOSSM) Orthopaedic Sports Medicine Fellowship Listing for 2020 to 2021 was reviewed to compile a list of all accredited fellowships in the United States. ${ }^{17}$ This list of orthopaedic sports medicine fellowship programs was cross-referenced with the SF Match 2020 fellowship listing to ensure accuracy. ${ }^{18}$ The FD for each program was then identified. Demographic, educational, and professional background data were collected for each FD via institutional biographies or publicly available curriculum vitae (CV). If information was not present on the fellowship program website or a CV was not publicly available, e-mailed questionnaires were sent to fellowship program administrators or coordinators requesting the desired information. If there was no response to the e-mail questionnaire, a followup phone call to the fellowship program administrator or coordinator was made.

The data collected for each FD included age, gender, race/ethnicity, past medical school location, past residency training location, past fellowship training location, residency and fellowship graduation years, additional advanced degrees, military affiliation, institutional loyalty, year hired by current institution, time since residency and fellowship completion until FD appointment, and length of time in FD role. Additionally, each FD's H-index, total number of publications, and total number of citations were collected.

An $\mathrm{H}$-index is a metric of scientific productivity and impact and is defined as the maximum value of $h$ such that the author in question has published $h$ papers that have been cited a minimum of $h$ times. ${ }^{19}$ For example, an author with an $\mathrm{H}$-index of 10 has 10 scientific publications that have all been cited a minimum of 10 times each. To obtain the $\mathrm{H}$-index, total number of publications, and total number of citations for each FD, the name was searched on the Scopus database (Elsevier BV, Waltham, MA). ${ }^{20}$ The Scopus database has an extensive record of peer-reviewed literature and tabulates scientific productivity metrics such as $\mathrm{H}$-index, total number of publications, and total number of citations for authors. Although no single citation tracking service can be entirely accurate or comprehensive, Scopus represents the most complete and precise option in regard to individual author citation and publication tracking. $^{21}$ Additionally, Scopus has been used by many previous analyses with the purpose of analyzing individual author research metrics. ${ }^{14,15,22-25}$ Publications were defined as pieces of scientific literature in which the author was included anywhere on the author line. The total number of citations were tabulated by the Scopus database and defined as the total number of citations in which the author was credited for any scientific work.

Leadership positions in 3 major orthopaedic and orthopaedic sports medicine societies were also analyzed. The Arthroscopy Association of North America (AANA), American Orthopaedic Society for Sports Medicine (AOSSM), and American Academy of Orthopaedic Surgeons (AAOS) were included in this investigation owing to their reputations as leading sports medicine and orthopaedic organizations with significant impact on the field. Leadership records were found on the organization's website by direct contact with the respective organization. To be recorded, a physician from the present analysis had to have served for $\geq 1$ year as president of 1 of these 3 major orthopaedic societies.

Statistical analysis included calculation of Pearson correlation coefficients. Calculations were made in Excel (Microsoft Corp., Redmond, WA). The correlation coefficients were interpreted according to Mukaka's guide on the appropriate use and analysis of correlation coefficients in medical research settings. ${ }^{26}$ Therefore, correlation coefficient values $<0.3,0.3$ to $0.5,0.5$ to 0.7 , and $>0.7$ to 0.9 , and $>0.9$ are suggestive of low, moderate, high, and very high positive correlation, respectively. 


\section{H-Indices of Fellowship Directors}

Figure 1. Demonstration of the Scopus Hindices for all orthopaedic sports medicine fellowship directors (as of December 1, 2020). Abbreviation: FD, fellowship director.

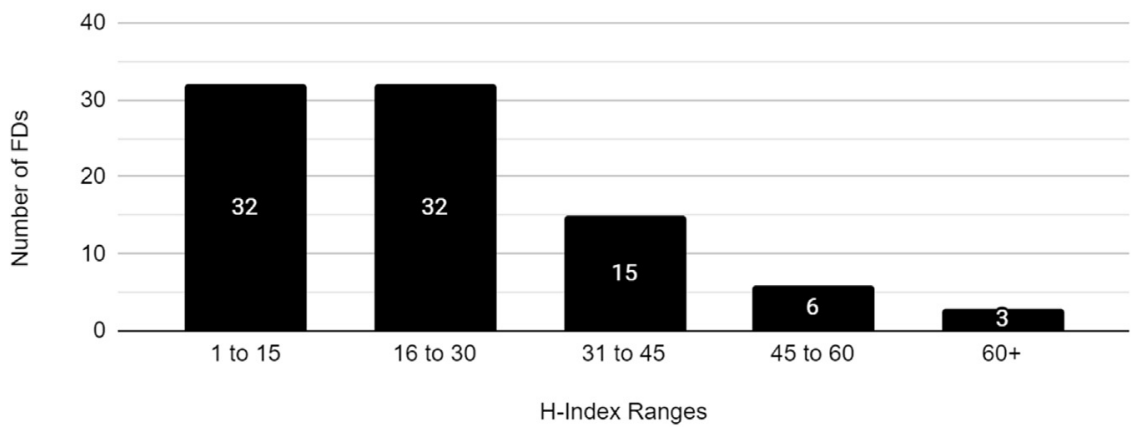

\section{Results}

According to the AAOSM 2020-2021 Sports Medicine Fellowship listing, there are a total of 88 accredited orthopaedic sports medicine fellowship programs. In our study, data was collected for 88 orthopaedic sports medicine FDs $(100 \%)$ representing 88 accredited orthopaedic sports medicine fellowship programs. Of the 88 FDs, $87(98.9 \%)$ were male and 1 ( $1.1 \%)$ was female. The age for all FDs was 54.7 years \pm 9.1 (mean \pm standard deviation). In total, 6 FDs had $\geq 1$ advanced degrees ( $1 \mathrm{PhD}, 3 \mathrm{MS} / \mathrm{MEd}$, and $4 \mathrm{MPH}$ ). One FD had both an MPH and an MS, and 1 FD had both an MPH and an MEd. A total of 16 FDs (18.2\%) had a military affiliation, and the mean Scopus $\mathrm{H}$-index, total number of publications, and total number of citations were 22.5 $\pm 16.6,90.0 \pm 91.6$, and $2773.9 \pm 3962.9$, respectively (Fig. 1). The research metrics for the 10 most prolific FDs is included in Table 1. The majority of FDs were White $(\mathrm{n}=80 ; 90.9 \%)$, followed by Asian $(\mathrm{n}=5$; $5.7 \%)$, Black or African American $(\mathrm{n}=2 ; 2.3 \%)$, and Hispanic or Latino $(\mathrm{n}=1 ; 1.1 \%)$.

The mean calendar years for the completion of orthopaedic residency training and fellowship training were $1998 \pm 9.8$ and $1999 \pm 9.5$, respectively. On average, it took $9.5 \pm 7.3$ years from fellowship graduation until FD appointment. Additionally, the mean number of years of employment or affiliation with their current institution was $17.2 \pm 9.4$, and the mean number of years in a FD role was $10.9 \pm 9.3$. Demographic and training data are summarized in Table 2.

The top 4 medical schools that trained future orthopaedic sports medicine FDs were Duke University School of Medicine $(\mathrm{n}=5)$, Georgetown University School of Medicine $(\mathrm{n}=5)$, Northwestern University Feinberg School of Medicine $(\mathrm{n}=3)$, and University of Pennsylvania School of Medicine $(n=3)$. Medical schools with $\geq 3$ FD affiliations are included in Figure 2.

The top 4 orthopaedic residency training programs that trained future FDs were the Hospital for Special Surgery (HSS) $(\mathrm{n}=11)$, Harvard University $(\mathrm{n}=5)$, Duke University $(\mathrm{n}=4)$, and Northwestern University $(n=4)$. Residency training programs with $\geq 3$ FD affiliations are included in Figure 3.

The top 4 orthopaedic sports medicine fellowship training programs that trained future FDs were the Steadman-Hawkins Clinic $(\mathrm{n}=9)$, the American Sports Medicine Institute $(\mathrm{n}=8)$, Hospital for Special Surgery $(\mathrm{n}=8)$, and the Kerlan-Jobe Orthopaedic Clinic $(\mathrm{n}=$ 8). Fellowship training programs with $\geq 3$ FD affiliations are included in Figure 4.

Regarding institutional loyalty, 10 FDs ( $11.4 \%$ ) direct programs affiliated with the institution at which they attended medical school. A total of 22 FDs $(25.0 \%)$ direct programs affiliated with the residency training

Table 1. Sports medicine fellowship leader research productivity (as of December 1, 2020)

\begin{tabular}{|c|c|c|c|c|}
\hline Fellowship Director & H-index & $\begin{array}{l}\text { Number of } \\
\text { Publications }\end{array}$ & $\begin{array}{l}\text { Number } \\
\text { of Citations }\end{array}$ & Fellowship Program Name \\
\hline Frank R. Noyes & 80 & 325 & 24,161 & $\begin{array}{l}\text { The Jewish Hospital Cincinnati/Cincinnati Sports Medicine } \\
\text { and Orthopaedic Center }\end{array}$ \\
\hline James R. Andrews & 75 & 347 & 20,210 & Andrews Research and Education Foundation \\
\hline Mininder S. Kocher & 61 & 284 & 11,647 & Children's Hospital (Boston) Program \\
\hline Marc J. Philippon & 58 & 269 & 11,005 & Steadman Philippon Research Institute Program \\
\hline Robert A. Arciero & 52 & 221 & 10,338 & University of Connecticut Program \\
\hline Robert H. Brophy, IV & 50 & 264 & 7928 & Washington University Program \\
\hline Christopher S. Ahmad & 49 & 313 & 7615 & Columbia University - New York Presbyterian Hospital Program \\
\hline Nikhil N. Verma & 46 & 325 & 7114 & Rush University Medical Center Program \\
\hline Volker Musahl & 46 & 329 & 6360 & University of Pittsburgh/UPMC Medical Education Program \\
\hline Dean C. Taylor & 43 & 132 & 7258 & Duke University Hospital Program \\
\hline
\end{tabular}


Table 2. Demographics, training background, education and employment progression, and leadership positions of orthopaedic sports medicine fellowship directors

\begin{tabular}{|c|c|}
\hline Criterion & Value \\
\hline \multicolumn{2}{|l|}{ Overall leadership } \\
\hline Total Number of Fellowship Programs & 88 \\
\hline Total Number of Fellowship Directors & 88 \\
\hline \multicolumn{2}{|l|}{ Demographics } \\
\hline Male & $87(98.9)$ \\
\hline Female & $1(1.1)$ \\
\hline Age $(y)$ & $54.7 \pm 9.1(\mathrm{n}=83)$ \\
\hline \multicolumn{2}{|l|}{ Advanced degrees } \\
\hline $\mathrm{PhD}$ & $1(1.1)$ \\
\hline MBA & $0(0.0)$ \\
\hline $\mathrm{MPH}$ & $4(4.5)$ \\
\hline MS/MEd & $3(3.4)$ \\
\hline \multicolumn{2}{|l|}{ Training and research } \\
\hline Military affiliation & $16(18.2)$ \\
\hline FD Scopus H-index & $22.5 \pm 16.6$ \\
\hline Number of total citations & $2773.9 \pm 3962.9$ \\
\hline Number of publications & $90.0 \pm 91.6$ \\
\hline \multicolumn{2}{|l|}{ Race/ethnicity } \\
\hline American Indian or Alaskan Native & $0(0.0)$ \\
\hline Asian & $5(5.7)$ \\
\hline Black or African American & $2(2.3)$ \\
\hline Hispanic or Latino & $1(1.1)$ \\
\hline Native Hawaiian or other Pacific Islander & $0(0.0)$ \\
\hline White & $80(90.9)$ \\
\hline \multicolumn{2}{|l|}{ Education and employment progression } \\
\hline Residency graduation calendar year & $1998 \pm 9.8(\mathrm{n}=68)$ \\
\hline Fellowship graduation calendar year & $1999 \pm 9.5(\mathrm{n}=67)$ \\
\hline $\begin{array}{l}\text { Time from fellowship graduation to FD } \\
\text { appointment }(\mathrm{y})\end{array}$ & $9.5 \pm 7.3(\mathrm{n}=40)$ \\
\hline $\begin{array}{l}\text { Duration of FD employment at current } \\
\text { institution }(\mathrm{y})\end{array}$ & $17.2 \pm 9.4(\mathrm{n}=51)$ \\
\hline Time in FD role $(y)$ & $10.9 \pm 9.3(\mathrm{n}=42)$ \\
\hline $\begin{array}{l}\text { Time from hiring to being appointed FD } \\
\text { (y) }\end{array}$ & $6.4 \pm 5.6(\mathrm{n}=39)$ \\
\hline \multicolumn{2}{|l|}{ Institutional loyalty } \\
\hline $\begin{array}{l}\text { FDs currently working at same institution } \\
\text { as medical school graduation }\end{array}$ & $10(11.4)$ \\
\hline $\begin{array}{l}\text { FDs currently working at same institution } \\
\text { as residency graduation }\end{array}$ & $22(25.0)$ \\
\hline $\begin{array}{l}\text { FDs currently working at same institution } \\
\text { as fellowship graduation }\end{array}$ & $24(27.3)$ \\
\hline \multicolumn{2}{|l|}{$\begin{array}{l}\text { Major orthopaedic sports medicine } \\
\text { leadership }\end{array}$} \\
\hline $\begin{array}{l}\text { FDs with a current or previous } \\
\text { appointment as president in a major } \\
\text { orthopaedic or sports medicine society }\end{array}$ & $5(5.7)$ \\
\hline AOSSM president & $2(2.3)$ \\
\hline AANA president & $2(2.3$ \\
\hline AAOS president & $1(1.1)$ \\
\hline \multicolumn{2}{|l|}{ Correlated H-indices } \\
\hline Years as FD versus Scopus H-index & $0.48(.001)^{*}$ \\
\hline Age versus Scopus $\mathrm{H}$-index & $0.35(.001)^{*}$ \\
\hline
\end{tabular}

program from which they graduated, and 24 FDs $(27.3 \%)$ direct programs affiliated with their fellowship training location. A total of 5 FDs $(5.7 \%)$ were previous presidents of 1 of the 3 major orthopaedic societies included in this analysis (AAOSM, $\mathrm{n}=2$ [2.3\%]; AANA, $\mathrm{n}=2[2.3 \%]$; and AAOS, $\mathrm{n}=1[1.1 \%]$ ).

Calculation of Pearson correlation coefficients revealed a significant low positive correlation between the number of years as FD versus Scopus H-index $(r=0.48 ; P=.001)$ and FD age versus Scopus H-index $(r=0.35 ; P=.001)$.

\section{Discussion}

This study revealed that the majority of orthopaedic sports medicine FDs are male $(98.9 \%)$, white $(90.9 \%)$, in their mid-50s, and prolific in research; have no advanced degrees outside of an MD (93.2\%); and have spent approximately 10.9 years in the FD position. Perhaps the most impactful observation was the level of research productivity and aptitude among orthopaedic sports medicine FDs. The mean $\mathrm{H}$-index and total number of publications among all orthopaedic sports medicine FDs were 22.5 and 90.0, respectively. Additionally, 56 FDs $(63.6 \%)$ had an $\mathrm{H}$-index score $>15$, with $1 \mathrm{FD}$ achieving an $\mathrm{H}$-index of 80 . In total, the 88 FDs in this analysis accumulated nearly a quarter million total citations $(244,103)$ from 7917 total scientific publications.

To help put these metrics in context, a study by Bastian et al. $^{23}$ found that among 2061 academic orthopaedic surgeons, the mean $\mathrm{H}$-index value for an orthopaedist in a chair position (the highest rank given in the study), was 17.8. Two similar studies characterizing FD leadership characteristics in orthopaedic adult reconstruction and orthopaedic/neurologic spine surgeons found mean $\mathrm{H}$-indices of 16.5 and 23.8, respectively. ${ }^{14,15}$ These findings could suggest a strong preference for academic and scientific prowess in the acquisition of an FD role in not only orthopaedic surgery, but particularly orthopaedic sports medicine. This quality may be highly favored in the field because of the significant impact that research activity has in shaping a rapidly advancing field such as orthopaedic sports medicine.

Additionally interesting was the effect that orthopaedic training pedigree had on FD position attainment. In regard to residency training, more than a quarter of the FDs included in this study attended 1 of 4 programs. The most attended residency programs were HSS $(\mathrm{n}=$ 11), Harvard University ( $\mathrm{n}=5)$, Duke University $(\mathrm{n}=$ $4)$, and Northwestern University $(\mathrm{n}=4)$. This trend was further amplified when it came to fellowship training. Over a third of all FDs in this study trained at 1 of 4 programs: Steadman-Hawkins Clinic $(\mathrm{n}=9)$, American Sports Medicine institute $(\mathrm{n}=8)$, Kerlan-Jobe Orthopaedic Clinic $(\mathrm{n}=8)$, and HSS $(\mathrm{n}=8)$. Although the focus of the current analysis was not to determine why these institutions have produced such a large proportion of orthopaedic sports medicine FDs, it is worth commenting on factors that may have played a role. It is 


\section{Most Commonly Attended Medical Schools}

Figure 2. The most attended medical schools among current orthopaedic sports medicine fellowship directors. All medical schools with $\geq 3$ previous orthopaedic sports medicine fellowship director graduates were included. Abbreviation: FD, fellowship director.

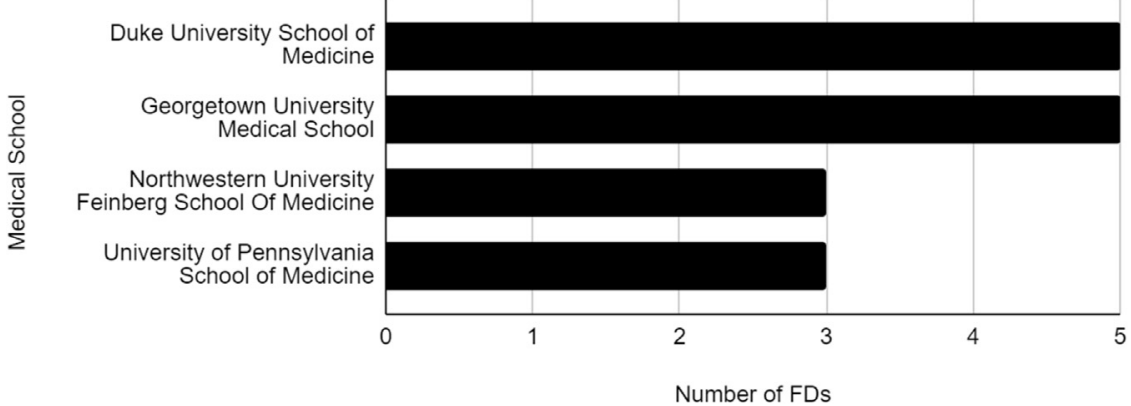

possible that the programs mentioned above offer curriculums and opportunities for training and research that prepare orthopaedic attendings particularly well for a career as an FD. These programs may also seek out physicians with aspirations to pursue high-level academic leadership positions such as FD. Applicants with leadership goals like this in mind will likely demonstrate a strong track record of previous leadership potential. Furthermore, the impact of professional networking and hierarchy should not be forgotten. It is likely that these institutions offer trainees unique opportunities to network with other leaders in the field of orthopaedic sports medicine that may lead to academic leadership appointments later in their careers. A hierarchy of training most certainly exists within orthopaedic sports medicine regardless of the causative factors. This trend is not totally unfounded, as similar studies analyzing the leadership trends in spine surgery and adult reconstruction surgery FDs found strong evidence of FD training histories being concentrated at a handful of institutions. ${ }^{14,15}$

When considering the amount of time it takes to become a FD after completing fellowship or being hired/affiliated with an institution, orthopaedic sports medicine is similar to other fields such as adult reconstruction and spine surgery. The mean number of years between fellowship completion and FD appointment was 9.5 in sports medicine, 9.6 in adult reconstruction, and 8.6 in spine surgery. ${ }^{14,15}$ Similarly, the mean number of years between the year of hire and the year promoted to FD was 6.4 in sports medicine, 5.5 in adult reconstruction, and 4.7 in spine surgery. Interestingly, the mean number of years that a FD was in the current role was 10.9 for sports medicine, whereas adult reconstruction and spine surgery had shorter tenures (8.2 and 9.7, respectively). ${ }^{14,15}$ This may suggest that the timeline from completion of residency and fellowship to FD appointment is consistent between orthopaedic fields, but the amount of time spent in the role of FD may vary depending on subspecialty.

We discovered a lack of gender and racial diversity in the FDs included in this study. The majority of orthopaedic sports medicine FDs are white males in their mid-50s. Only 1 FD was female, and $<10 \%$ were non-White. This was not surprising, as the field of orthopaedic surgery has long been criticized for its homogeneous workforce. ${ }^{27-29}$ As of 2018, the orthopaedic workforce as a whole was $92.3 \%$ male and $84.7 \%$ Caucasian $(6.7 \%$ Asian, 2.2\% Hispanic/Latino, 1.9\% African American, and $0.4 \%$ Native American). ${ }^{30}$ Additionally, in 2019 the orthopaedic sports medicine workforce was $93.1 \%$ male. $^{31}$

\section{Most Commonly Attended Residency Training Institutions}

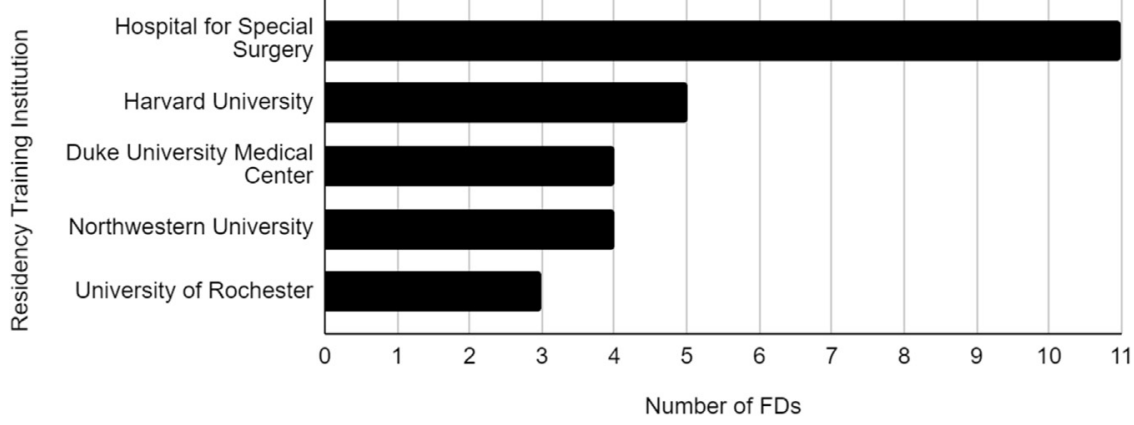

Figure 3. The most attended orthopaedic residency training institutions among current orthopaedic sports medicine fellowship directors. All residency training programs with $\geq 3$ previous orthopaedic sports medicine fellowship director graduates were included. Abbreviation: FD, fellowship director. 


\section{Most Commonly Attended Fellowship Training Institutions}

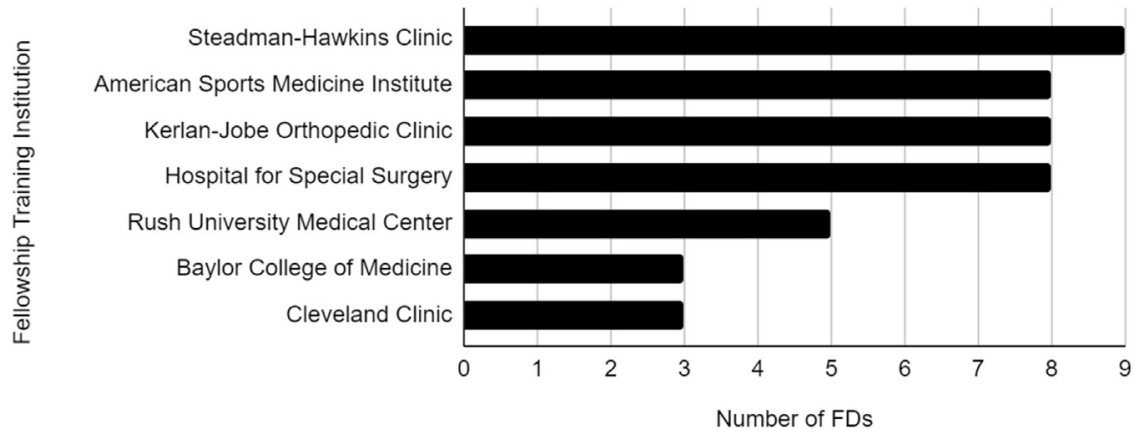

Figure 4. The most attended orthopaedic sports medicine fellowship training institutions among current orthopaedic sports medicine fellowship directors. All fellowship training programs with $\geq 3$ previous orthopaedic sports medicine fellowship director graduates were included. Abbreviation: FD, fellowship director.

Historically, orthopaedic surgery has been a maledominated field with little representation by women or minorities. The rate of growth in female representation within orthopaedic surgery has risen slightly over the past 2 decades, but it would take nearly 85 years at the current rate of growth for women to reach just a $30 \%$ representation in the field. ${ }^{32}$ The rate of growth for minority representation has also increased but lags significantly behind other surgical fields such as urology, ophthalmology, and neurosurgery. ${ }^{33}$ As shown in this analysis, the gender and racial disparity in orthopaedics extends to the highest leadership positions, and it may take decades before an increasing number of women and minorities entering the field finally reach a stage in their career to be appointed into leadership. Furthermore, for $>30$ years, women in orthopaedic surgery have been less represented in the scientific literature. ${ }^{34}$ Research accomplishment is an incredibly important factor in obtaining an FD role; therefore, improving the representation of female and minority surgeons in both the field of orthopaedic surgery and leadership positions depends on expanding the research and training opportunities these populations have access to.

\section{Limitations}

This study was not without limitations. First, the data collection process for this study relied on obtaining selfreported data in the form of website biographies and CVs. It is possible that information reported in CVs may be inaccurate or outdated at the time of data collection. However, researchers corroborated pieces of information from multiple sources and clarified ambiguous information with emails to FDs or fellowship representatives. Additionally, contact with an FD could not always be made, and fellowship administrators were often contacted to solicit missing data to no avail. Thus, some FDs were unable to be contacted, and pieces of data had to be excluded. The data in this study represent a cross-sectional representation of the demographic trends in orthopaedic sports medicine FDs at a single point in time. FD positions may change from year to year at some institutions, which would not be captured in this analysis. Furthermore, this is not a comprehensive assessment of all the traits that may contribute to an FD's success in the field of orthopaedic sports medicine.

\section{Conclusions}

Orthopaedic sports medicine fellowship directors are largely distinguished by their high level of research productivity and accomplishment. Additionally, orthopaedic training pedigree seems to play a role in FD role attainment, with a handful of orthopaedic residency and sports medicine fellowship programs producing a large percentage of current FDs. Finally, FDs are overwhelmingly white males, with little female or minority representation.

\section{References}

1. Yayac M, Javandal M, Mulcahey MK. Accredited orthopaedic sports medicine fellowship websites: An updated assessment of accessibility and content. Orthop J Sports Med 2017;5:2325967116683942.

2. Daniels AH, DiGiovanni CW. Is subspecialty fellowship training emerging as a necessary component of contemporary orthopaedic surgery education? J Grad Med Educ 2014;6:218-221.

3. Ruddell JH, Eltorai AEM, DePasse JM, et al. Trends in the orthopaedic surgery subspecialty fellowship match: Assessment of 2010 to 2017 applicant and program data. J Bone Joint Surg Am 2018;100:e139.

4. Horst PK, Choo K, Bharucha N, et al. Graduates of orthopaedic residency training are increasingly subspecialized: A review of the American Board of Orthopaedic Surgery part ii database. J Bone Joint Surg Am 2015;97:869-875.

5. Rao RD, Khatib ON, Agarwal A. Factors motivating medical students in selecting a career specialty: Relevance for a robust orthopaedic pipeline. I Am Acad Orthop Surg 2017;25:527-535. 
6. Matson AP, Kavolus JJ, Byrd WA, et al. Influence of trainee experience on choice of orthopaedic subspecialty fellowship. J Am Acad Orthop Surg 2018;26:e62-e67.

7. Kavolus JJ, Matson AP, Byrd WA, et al. Factors influencing orthopaedic surgery residents' choice of subspecialty fellowship. Orthopaedics 2017;40:e820-e824.

8. Schrock JB, Kraeutler MJ, Dayton MR, et al. A crosssectional analysis of minimum USMLE step 1 and 2 criteria used by orthopaedic surgery residency programs in screening residency applications. J Am Acad Orthop Surg 2017;25:464-468.

9. Grabowski G, Walker JW. Orthopaedic fellowship selection criteria: A survey of fellowship directors. J Bone Joint Surg Am 2013;95:e154.

10. Baweja R, Kraeutler MJ, Mulcahey MK, et al. Determining the most important factors involved in ranking orthopaedic sports medicine fellowship applicants. Orthop J Sports Med 2017;5:2325967117736726.

11. Ford HR, Upperman JS, Lim JC. What does it mean to be an underrepresented minority leader in surgery? In: Kibbe MR, Chen H (eds) Leadership in Surgery. Cham, Switzerland: Springer International, pp. 183-193.

12. Rohde RS, Wolf JM, Adams JE. Where are the women in orthopaedic surgery? Clin Orthop 2016;474:1950-1956.

13. Filiberto AC, Le CB, Loftus TJ, et al. Gender differences among surgical fellowship program directors. Surgery 2019;166:735-737.

14. Schiller NC, Donnally CJ, Sama AJ, et al. Trends in leadership at orthopaedic surgery adult reconstruction fellowships. J Arthroplasty 2020;35:2671-2675.

15. Donnally CJ, Schiller NC, Butler AJ, et al. Trends in leadership at spine surgery fellowships. Spine 2020;45: E594-E599.

16. Addona T, Polcino M, Silver L, et al. Leadership trends in plastic surgery. Plast Reconstr Surg 2009;123:750-753.

17. Fellowship Listing, https://www.sportsmed.org/ AOSSMIMIS / Applications/Fellowship_Listing.aspx. Accessed November 23, 2020.

18. Residency and Fellowship Match, https://sfmatch.org/ SubSpecialties.aspx?id=32\&typ $=1$. Accessed November 23, 2020.

19. Welzenbach R. Research Guides: Research Impact Metrics: Citation Analysis: H-Index, https://guides.lib.umich. edu/c.php? $\mathrm{g}=282982 \mathrm{sp}=1887449$. Accessed November 23, 2020.

20. Scopus preview - Scopus - Welcome to Scopus, https:// WwW.scopus.com/home.uri? zone $=$ headersorigin $=$. Accessed November 23, 2020.
21. Falagas ME, Pitsouni EI, Malietzis GA, et al. Comparison of PubMed, Scopus, Web of Science, and Google Scholar: Strengths and weaknesses. FASEB J 2008;22:338-342.

22. Sama AJ, Schiller NC, Ramirez CM, et al. Leadership trends among orthopaedic trauma surgery fellowship directors: A cross-sectional demographic review. Curr Orthop Pract 2021;32:107-111.

23. Bastian S, Ippolito JA, Lopez SA, et al. The use of the hindex in academic orthopaedic surgery. J Bone Joint Surg Am 2017;99:e14.

24. Silvestre J, Kamath A. Prevalence and impact of selfcitation in academic orthopaedic surgery. Am J Orthop Belle Mead NJ 2018;47. doi:10.12788/ajo.2018.0015.

25. Stavrakis AI, Patel AD, Burke ZDC, et al. The role of chairman and research director in influencing scholarly productivity and research funding in academic orthopaedic surgery. J Orthop Res 2015;33:1407-1411.

26. Mukaka MM. Statistics corner: A guide to appropriate use of correlation coefficient in medical research. Malawi Med J 2012;24:69-71.

27. Day MA, Owens JM, Caldwell LS. Breaking barriers: A brief overview of diversity in orthopaedic surgery. Iowa Orthop J 2019;39:1-5.

28. Bernstein J. Male practice: Gender inequality in orthopaedic surgery. Clin Orthop 2013;471:1754-1757.

29. Harrington MA, Rankin EA, Ladd AL, et al. The orthopaedic workforce is not as diverse as the population it serves: Where are the minorities and the women? AOA Critical Issues Symposium. J Bone Joint Surg Am 2019;101: e31.

30. AAOS Now September 2019: A Snapshot of U.S. orthopaedic surgeons: Results from the 2018 OPUS Survey, https://www.aaos.org/aaosnow/2019/sep/youraaos/ youraaos01/. Accessed April 20, 2021.

31. Active Physicians by Sex and Specialty, 2019. AAMC https://www.aamc.org/data-reports/workforce/inter active-data/active-physicians-sex-and-specialty-2019. Accessed April 20, 2021.

32. Cero S. AAOS Now June 2019: Making the Case (Again) for Gender Equity, https://Www.aaos.org/aaosnow/2019/ jun/youraaos/youraaos05/. Accessed December 6, 2020.

33. Poon S, Kiridly D, Mutawakkil M, et al. Race and ethnic diversity in orthopaedic surgery residency. Pediatrics 2018;141:642.

34. Brown MA, Erdman MK, Munger AM, et al. Despite growing number of women surgeons, authorship gender disparity in orthopaedic literature persists over 30 years. Clin Orthop Relat Res 2020;478:1542-1552. 